\title{
Chitosan as a Drinking Water Treatment Coagulant
}

\author{
Frederick W. Pontius \\ Department of Civil Engineering, California Baptist University, Riverside, California, USA
}

\section{Email address:}

fpontius@calbaptist.edu

\section{To cite this article:}

Frederick W. Pontius. Chitosan as a Drinking Water Treatment Coagulant. American Journal of Civil Engineering. Vol. 4, No. 5, 2016, pp. 205-215. doi: 10.11648/j.ajce.20160405.11

Received: June 11, 2016; Accepted: July 9, 2016; Published: July 15, 2016

\begin{abstract}
Inorganic aluminum or iron salts have been used for many decades to coagulate colloidal particles in surface water prior to flocculation, sedimentation and/or filtration. Although effective, inorganic coagulants have several disadvantages including large chemical dosages required for treating eutrophic waters, large volumes of chemical sludge produced, and toxic effects of metallic coagulants on the aquatic environment. Chitosan is a natural cellulose-like copolymer of glucosamine and $\mathrm{N}$-acetyl-glucosamine. Because of their biodegradability chitosan-based materials have been suggested as a more eco-friendly coagulant for water and wastewater treatment. Chitosan was an effective coagulant in several prior laboratory studies. Practical application of chitosan as a drinking water treatment coagulant is evaluated here through a series of jar tests. The effectiveness of chitosan is compared to aluminum sulphate and ferric chloride with regard to treatment of algal-ladened waters. The optimum chemical dose for coagulation, optimum $\mathrm{pH}$, and effectiveness for algae removal was determined for each coagulant. Practical aspects of applying chitosan at full-scale and the impact of feeding this chemical on overall treated water quality are addressed.
\end{abstract}

Keywords: Chitosan, Coagulation, Water Treatment

\section{Introduction}

Coagulation is used in drinking water treatment to destabilize colloidal suspensions in order to remove turbidity and natural organic matter (NOM). Inorganic coagulants are most commonly used for this purpose although synthetic polymers also have application. Although effective, inorganic coagulants such as aluminum sulfate (alum) have distinct disadvantages. These include limited availability in certain regions, large chemical dosages required for treating eutrophic waters, large quantities of chemical sludge produced, and harmful effects of residual metallic coagulants on the aquatic environment [1].

Chitin is a natural polymer derived primarily from two marine crustaceans, shrimp and crabs. The most important derivative of chitin is chitosan (Figure 1) obtained by partial de acetylation of chitin under alkaline conditions or enzymatic hydrolysis [2]. Chitosan is a non-toxic linear high molecular weight cationic polymer exhibiting a variety of properties. It has a variety of applications in cosmetics, biomedical engineering, agriculture, nutrition and many other fields. Chitosan-based materials have also been suggested as potentially eco-friendly coagulants and flocculants for water and wastewater treatment because of their natural biological characteristics and biodegradability [3].

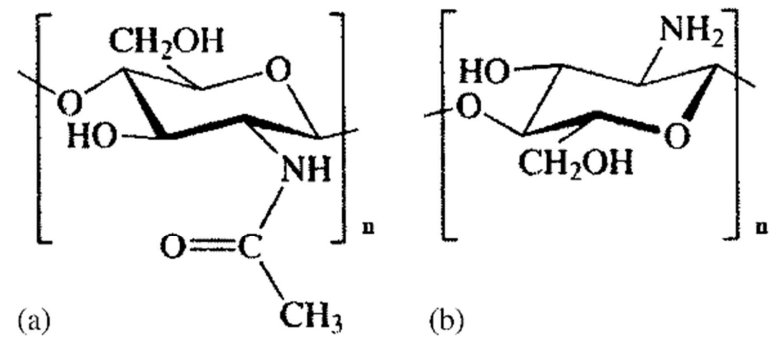

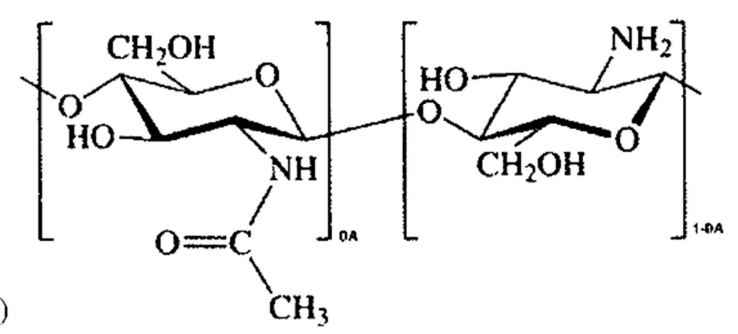

Figure 1. Chemical structure (a) of chitin poly(N-acetyl- $\beta$-D-glucosamine) and (b) of chitosan (poly(D-glucosamine)) repeat units. (c) Structure of partially acetylated chitosan, a copolymer characterized by its average degree of acetylation. From Rinaudo (2006) [2]. 
In laboratory studies chitosan has been reported to perform well as a coagulant for removing Chlorella sp. in algal turbid water [4], removing turbidity from sea water [5], and for microalgae harvesting [6]. It has several industrial and commercial uses, can be recycled, and is an excellent chelating agent for many metals such as arsenic, molybdenum, cadmium, chromium, lead, and cobalt [7].

Chitosan has received limited study as a drinking water coagulant. The chemical modification methods used to prepare chitosan-based flocculants and the influence of structural elements on flocculation properties and mechanisms have been recently reviewed [8]. The practical application of chitosan as a water treatment coagulant is examined in the study presented here.

\section{Experimental Methods}

The performance of chitosan for coagulation was evaluated by jar testing using a factorial experimental design.

\subsection{Water Samples}

Lake Evans, located in Fairmont Park, Riverside, CA was selected for sampling because it is typical of surface waters in the surrounding area, has a large waterfowl population, experiences algal growth during the summer months, and is readily accessible. Samples of lake water were taken in 5-gallon carboy containers and transported to the laboratory. If necessary, water samples were preserved and stored following US Environmental Protection Agency (EPA) accepted procedures and analyzed within required sample holding times [9].

\subsection{Coagulants}

The effectiveness of chitosan as a coagulant was evaluated by comparing its performance to aluminum sulfate in a series of jar tests. No attempt was made to optimize coagulant selection for this particular water. Only the relative performance of three coagulants was evaluated. To simulate operational conditions at a water treatment plant tap water was used to prepare all coagulant stock solutions.

\subsubsection{Chitosan}

Chitosan is insoluble in either water or organic solvents. In dilute organic acids such as acetic acid and inorganic acids (e.g. $\mathrm{HCl}$ ), the free amino groups are protonated and the biopolymer becomes fully soluble. Consequently researchers have employed different approaches to prepare chitosan stock solutions for jar testing. The approach of Divakaran and Pillai (2001) [10] using dilute hydrochloric acid was applied here because it more closely represented procedures that would be used to prepare a chitosan feed solution at a water treatment plant.

One hundred $\mathrm{mg}$ of commercially available chitosan oligosaccharide powder (Qingdao BZ Oligo Biotech Co., Ltd., China) was placed in a glass beaker and mixed with 10 $\mathrm{mL}$ of $0.1 \mathrm{M} \mathrm{HCl}$ and set aside for 1 hour to completely dissolve. The solution was diluted to $100 \mathrm{~mL}$ with tap water to yield a $1 \mathrm{mg}$ chitosan per $\mathrm{mL}$ stock solution. Hereafter this solution is referred to as "chitosan."

\subsubsection{Aluminum Sulfate}

Five hundred $\mathrm{mg}$ of $\mathrm{Al}_{2}\left(\mathrm{SO}_{4}\right)_{3} \cdot \mathrm{xH}_{2} \mathrm{O}$ was placed in a 500-mL volumetric flask and diluted to the mark using tap water resulting in a $1 \mathrm{mg}$ aluminum sulphate per mL stock solution. Hereafter this solution is referred to as "alum."

\subsubsection{Ferric Chloride}

Five hundred mg of $\mathrm{FeCl}_{3} \cdot 6 \mathrm{H}_{2} \mathrm{O}$ was placed in a $500-\mathrm{mL}$ volumetric flask and diluted to the mark using tap water resulting in a $1 \mathrm{mg}$ ferric chloride per $\mathrm{mL}$ stock solution. Hereafter this solution is referred to as "ferric."

\subsection{Jar Tests}

A series of jar tests were conducted following ASTM D 2035-08, Standard Practice for Coagulation-Flocculation Jar Test of Water [11]. Coagulants were added with rapid mixing for 2 minutes, slow mixing for 30 minutes (tapered at 10 minute intervals); and settling for 45 minutes. Aliquots were taken from each jar for analysis.

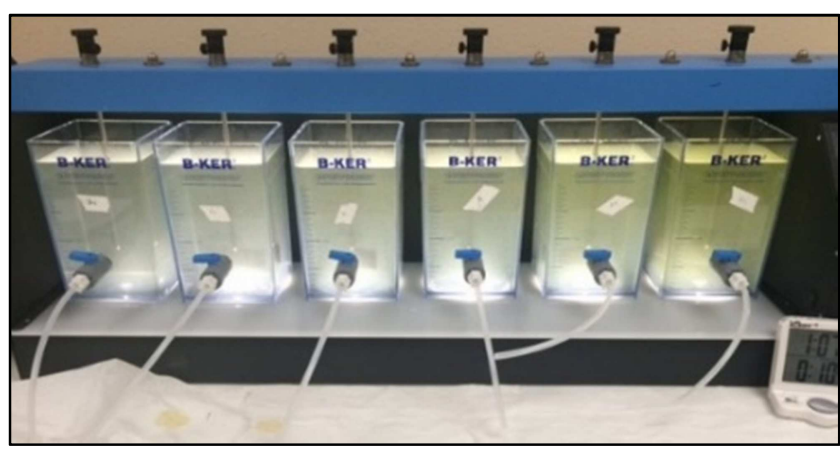

Figure 2. Jar test with algae spike.

A series of 4 jar tests ( 6 jars per test) were conducted for each coagulant. The first jar test was a trial run to gain experience in estimating chemical dosages and performing laboratory analyses. The second jar test determined the optimum dose for each coagulant. For the second jar test the $\mathrm{pH}$ of each jar was adjusted using a dropper bottle of $0.1 \mathrm{~N}$ $\mathrm{HCl}$. The third jar test identified the optimum $\mathrm{pH}$ for coagulation at the previously determined optimum dose. The fourth jar test assessed the removal of high algal concentrations typical of eutrophic surface waters at the previously determined optimum dose and optimum $\mathrm{pH}$ (Figure 2). Each jar was spiked with a living-mixed algal suspension culture grown in the laboratory from commercially available stock (Cyanobacteria mixture; Carolina Supply Cat. \# 199980) using Alga Grow ${ }^{\circledR}$ media (Carolina Supply Cat. \#15-3751).

\subsection{Analytical Methods}

All analyses were performed at the California Baptist University (CBU) environmental engineering laboratory. The analytes and analytical methods used for chemical analyses performed on samples from each jar are presented in Table 1. 
Quality assurance (QA) and quality control (QC) measures were followed along with standard laboratory practices for instrument calibration according following the manufacturer's instructions.

Turbidity was measured on the settled water from each jar, settled water filtered through Whatman $40(8 \mu \mathrm{m})$ filter paper, and settled water filtered through a $0.45 \mu \mathrm{m}$ PVDF syringe membrane filter (Fisherbrand ${ }^{\mathrm{TM}}$ Durapore $^{\mathrm{TM}}$ ). Filtration through a $0.45 \mu \mathrm{m}$ membrane filter was also performed prior to ultraviolet absorbance (UVA).

Microbiological testing was performed on selected samples. Total Coliform (TC) and E. coli (EC) analyses were conducted using the membrane filter method and $\mathrm{m}$-ColiBlue24® following USEPA-approved procedures [13]. Algae counts were made using a Sedgwick-Rafter cell in accordance with Method 8110 of Standard Methods [12].

Table 1. Chemical Analytical Methods.

\begin{tabular}{|c|c|c|}
\hline Analyte & Technique & Analytical Method \\
\hline Alkalinity & Titrimetric, $\mathrm{pH} 4.5$ & EPA Method 310.1 \\
\hline $\begin{array}{l}\text { Biochemical } \\
\text { Oxygen Demand } \\
\text { (BOD) }\end{array}$ & Incubation, 5-day & EPA Method 405.1 \\
\hline $\begin{array}{l}\text { Chemical } \\
\text { Oxygen Demand } \\
\text { (COD) }\end{array}$ & Reactor Digestion & EPA Method 410.4 \\
\hline Color & Platinum-Cobalt & $\begin{array}{l}\text { Adapted from Method } 2120 \\
\text { of Standard Methods [12] }\end{array}$ \\
\hline Hardness & Titrimetric, EDTA & EPA Method 130.2 \\
\hline Temperature & Thermometric & EPA Method 170.1 \\
\hline $\begin{array}{l}\text { Total Dissolved } \\
\text { Solids (TDS) }\end{array}$ & Gravimetric & EPA Method 160.1 \\
\hline $\begin{array}{l}\text { Total } \\
\text { Phosphorus }\end{array}$ & Persulfate Digestion & EPA Method 265.2 \\
\hline Turbidity & Nephelometer & EPA Method 180.1 \\
\hline $\begin{array}{l}\text { UV absorbance } \\
\text { (UVA) }\end{array}$ & UVA at $254 \mathrm{~nm}$ & EPA Method 415.3 \\
\hline
\end{tabular}

\section{Results and Discussion}

\subsection{Optimum Coagulant Dosages}

The first jar test series conducted compared chitosan and alum providing an opportunity to gain initial experience with these chemicals. The second series of jar tests evaluated the optimum dose for each coagulant. The coagulant dosages applied were based on prior experience with treating this particular water as well as prior published studies.

The optimum coagulant dose was based on settled water turbidity shown in Figure 3. The point-of-diminishing return for alum, chitosan, and ferric were $30 \mathrm{mg} / \mathrm{L}, 8 \mathrm{mg} / \mathrm{L}$, and 30 $\mathrm{mg} / \mathrm{L}$, respectively. This optimum chitosan dose is higher than that reported by Rizzo et al (2008) for turbidity removal [14] most likely due to differences in the waters tested and the characteristics of the chitosan applied. The optimum doses selected for alum and ferric are somewhat conservative but consistent with prior results for testing of this water source.

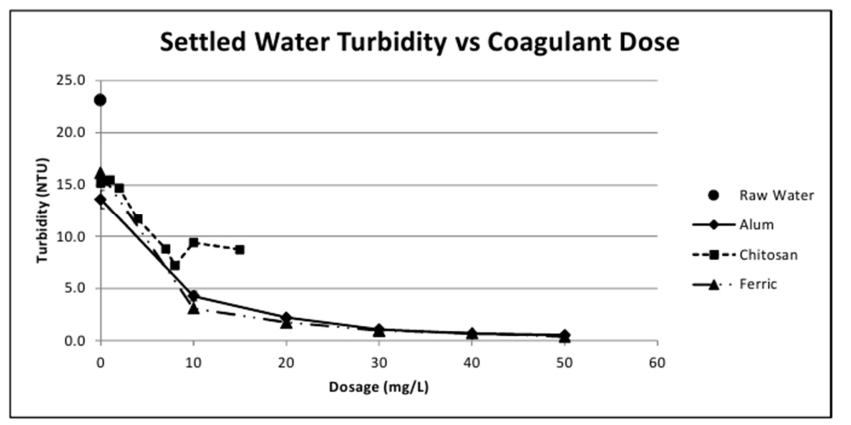

Figure 3. Settled water turbidity versus coagulant dose for alum, chitosan, and ferric.

\subsection{Turbidity Removal}

To assess the effectiveness of overall turbidity removal, settled water from each jar was filtered through Whatman Grade 40 filter paper $(8 \mu \mathrm{m})$ to simulate sand filtration. A separate aliquot of settled water was filtered using a $0.45 \mathrm{um}$ syringe membrane filter to produce membrane filtered water.

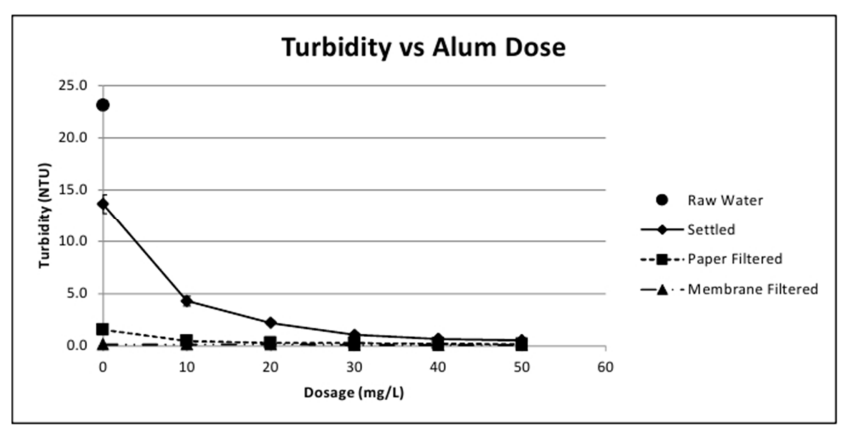

Figure 4. Turbidity removal vs alum dose for settled water, paper filtered water, and membrane filtered water.

Results of turbidity removal tests are shown in Figures 4, 5, and 6 for alum, chitosan, and ferric, respectively. Treated water turbidity at the optimum coagulant dose is summarized in Table 2. Each coagulant provided effective pretreatment to filtration. The combination of coagulation at the optimum dose, sedimentation, and paper filtration lowered treated water turbidity by $98.8,96.9$, and 98.9 percent for alum, chitosan, and ferric, respectively.

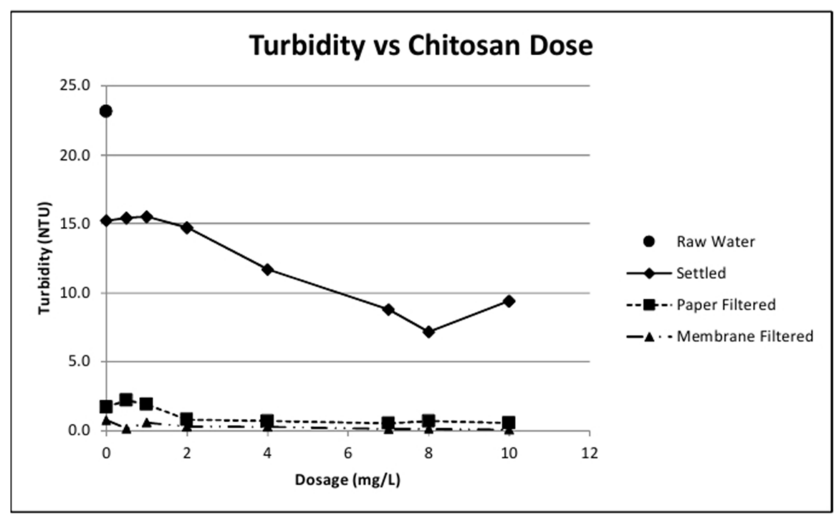

Figure 5. Turbidity removal vs chitosan dose for settled water, paper filtered water, and membrane filtered water. 
The combination of coagulation at the optimum dose, sedimentation, and membrane filtration lowered treated water turbidity by $99.6,99.4$, and 98.7 percent for alum, chitosan, and ferric, respectively. For chitosan, membrane filtration was required to meet the $0.3 \mathrm{NTU}$ turbidity limit set by USEPA.

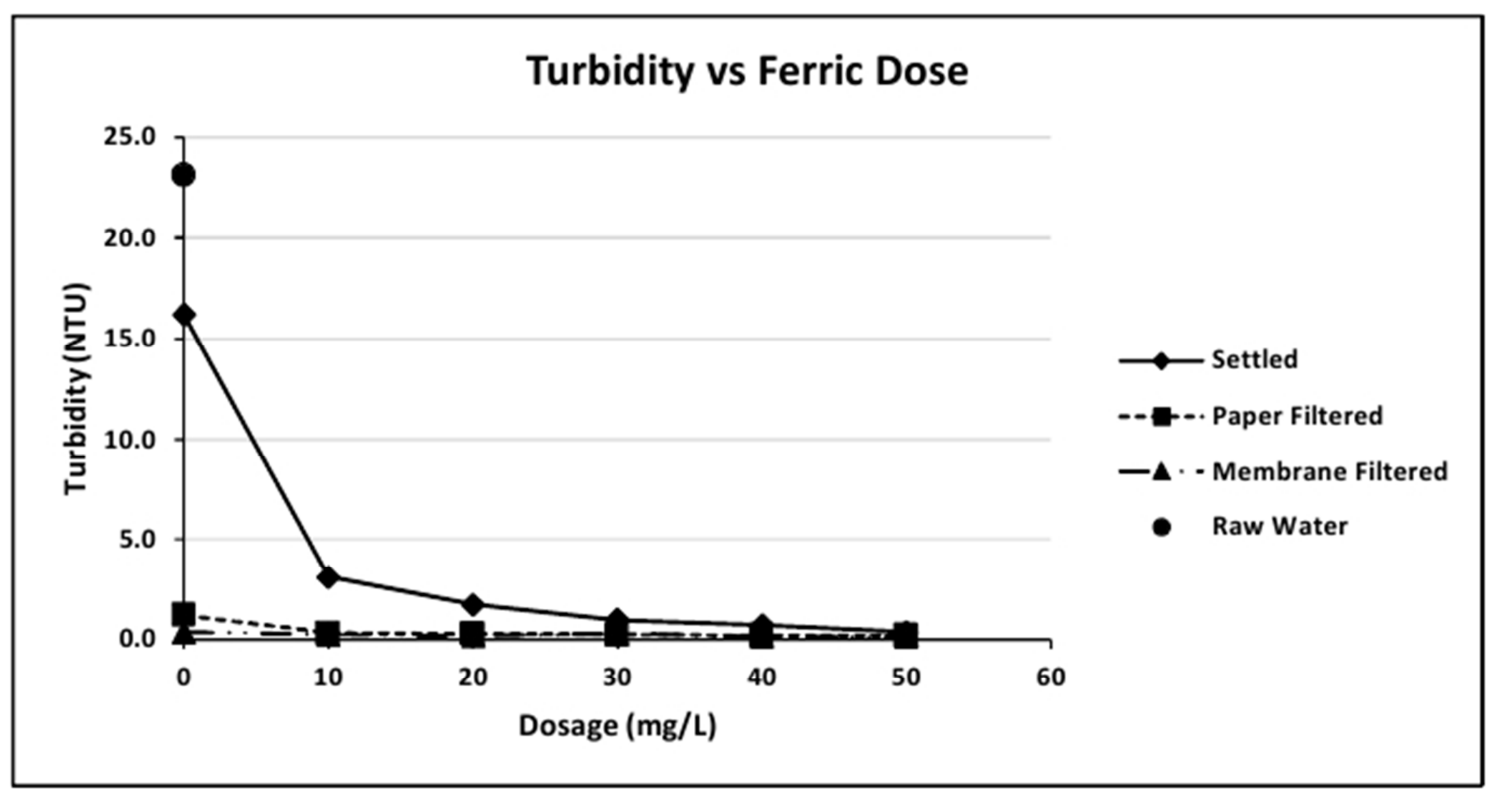

Figure 6. Turbidity removal vs ferric dose for settled water, paper filtered water, and membrane filtered water.

Table 2. Treated Water Turbidity at the Optimum Coagulant Dose (Turbidity Removal Percentage)*.

\begin{tabular}{llll}
\hline Coagulant & Settled water Turbidity NTU (\%) & Paper filtered water Turbidity NTU (\%) & Membrane filtered water Turbidity NTU (\%) \\
\hline Alum & $1.07(95.4 \%)$ & $0.28(98.8 \%)$ & $0.091(99.6 \%)$ \\
Chitosan & $7.19(68.9 \%)$ & $0.7(96.9 \%)$ & $0.14(99.4 \%)$ \\
Ferric & $0.967(95.8 \%)$ & $0.24(98.9 \%)$ & $0.28(98.7 \%)$ \\
\hline
\end{tabular}

$*$ Raw water turbidity $=23.1$ NTU

\subsection{Optimum pH for Coagulation}

The third series of jar tests evaluated the impact of $\mathrm{pH}$ on coagulation. The impact of $\mathrm{pH}$ on turbidity removal is shown in Figures 7, 8, and 9. For this particular water, $\mathrm{pH}$ had little impact on alum coagulation. As the $\mathrm{pH}$ was increased, chitosan was less effective as a coagulant based on settled water turbidity and paper filtered turbidity consistent with with Rizzo et al 2008 [14]. Increasing pH affected ferric coagulation somewhat based on paper filtered water turbidity. Membrane filtered water turbidity deteriorated with increasing $\mathrm{pH}$ suggesting less effective ferric coagulation of smaller colloidal particles. The $\mathrm{pH}$ selected for optimum settled water turbidity removal was 6.0, 5.5 and 5.5 for alum, chitosan, and ferric coagulation, respectively.

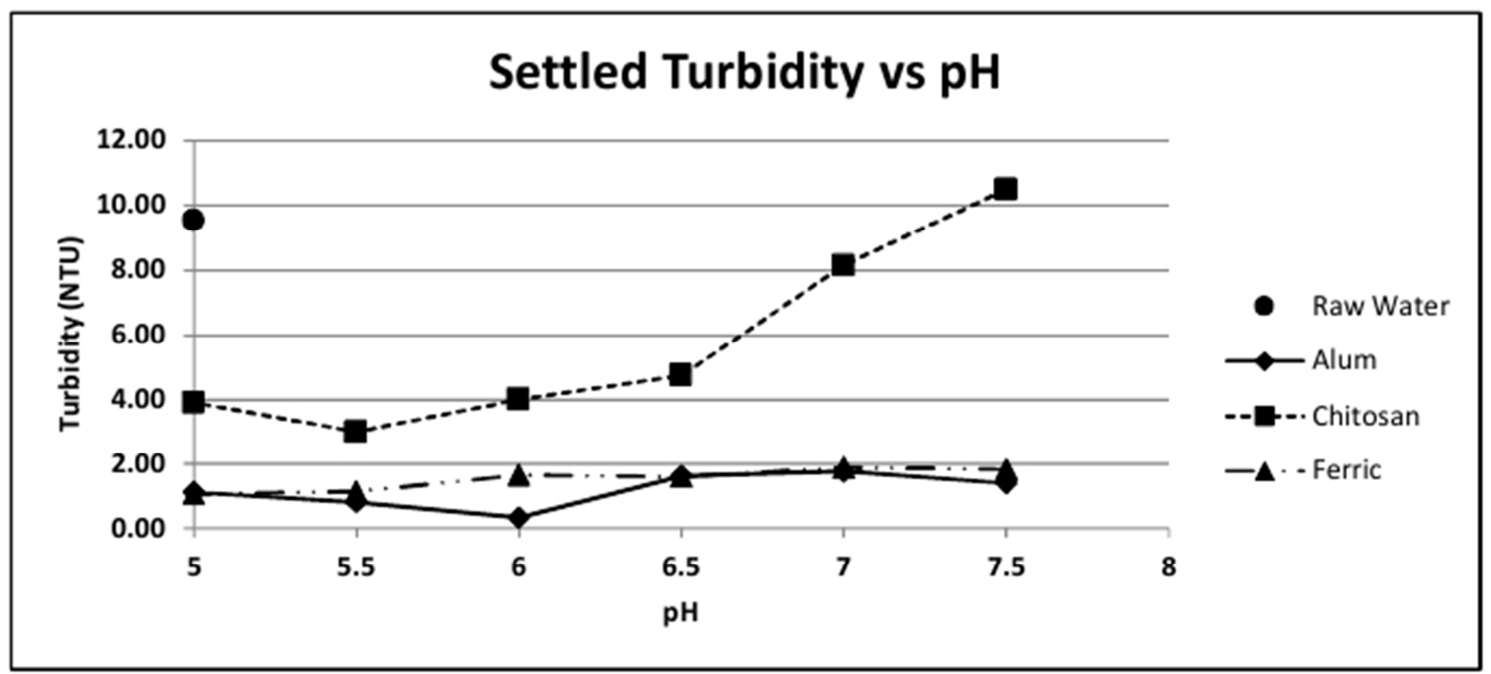

Figure 7. Settled turbidity vs pH at the optimum coagulant dose for settled water. 


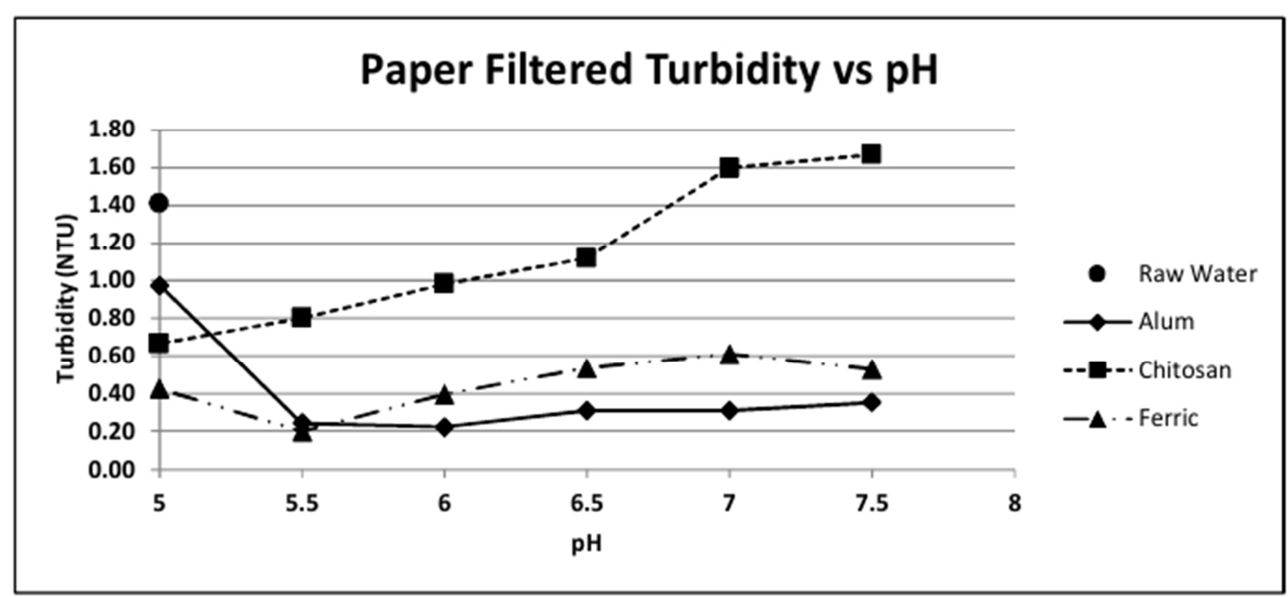

Figure 8. Paper Filtered turbidity vs pH at the optimum coagulant dose for settled water.

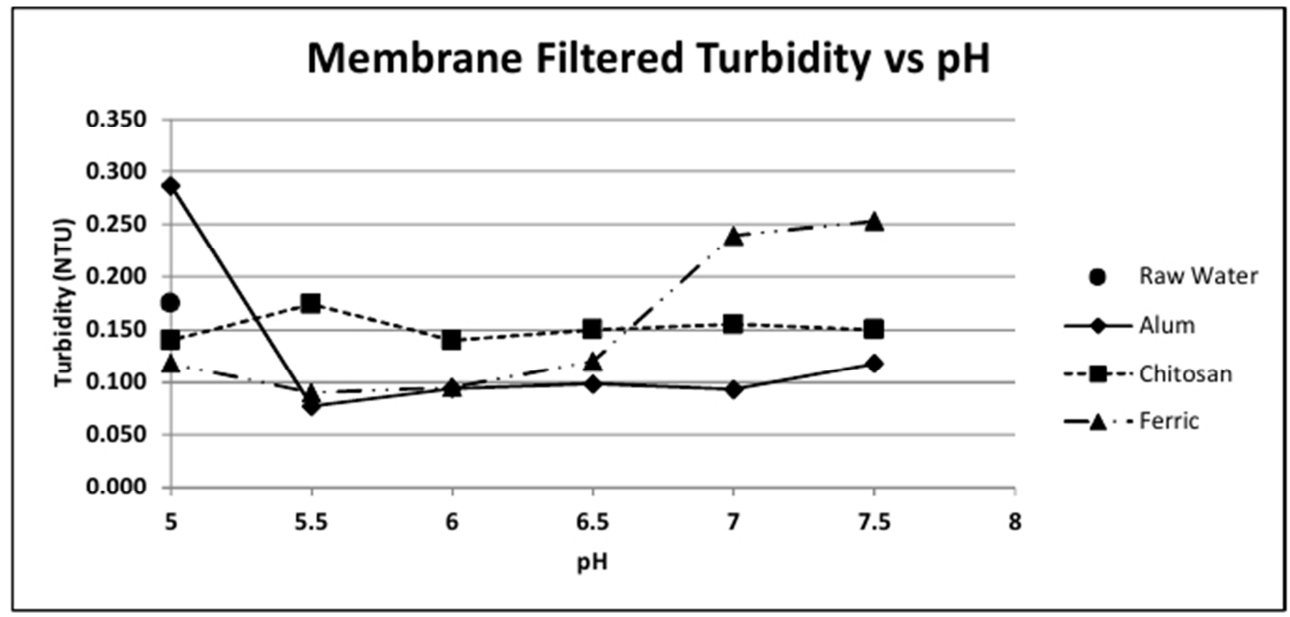

Figure 9. Membrane filtered turbidity vs pH at the optimum coagulant dose for settled water.

\subsection{Organic Matter Removal}

$\mathrm{BOD}_{5}, \mathrm{COD}$, and UVA) were used as surrogate measures to evaluate removal of organic matter. The third series of jar tests evaluated the impact of $\mathrm{pH}$ on coagulation (Figures 10,11, and 12). Alum and ferric consistently removed $\mathrm{BOD}_{5}$ as $\mathrm{pH}$ increased. For chitosan, $\mathrm{BOD}_{5}$ increased as the $\mathrm{pH}$ increased. With less efficient coagulation at the higher $\mathrm{pH}$, more biodegradable chitosan monomer remained in solution. Treated water COD levels were higher for chitosan than for alum or ferric. Treated water COD increased somewhat for all three coagulants as the $\mathrm{pH}$ increased. UVA increased as $\mathrm{pH}$ increased for all three coagulants with chitosan displaying the highest values.

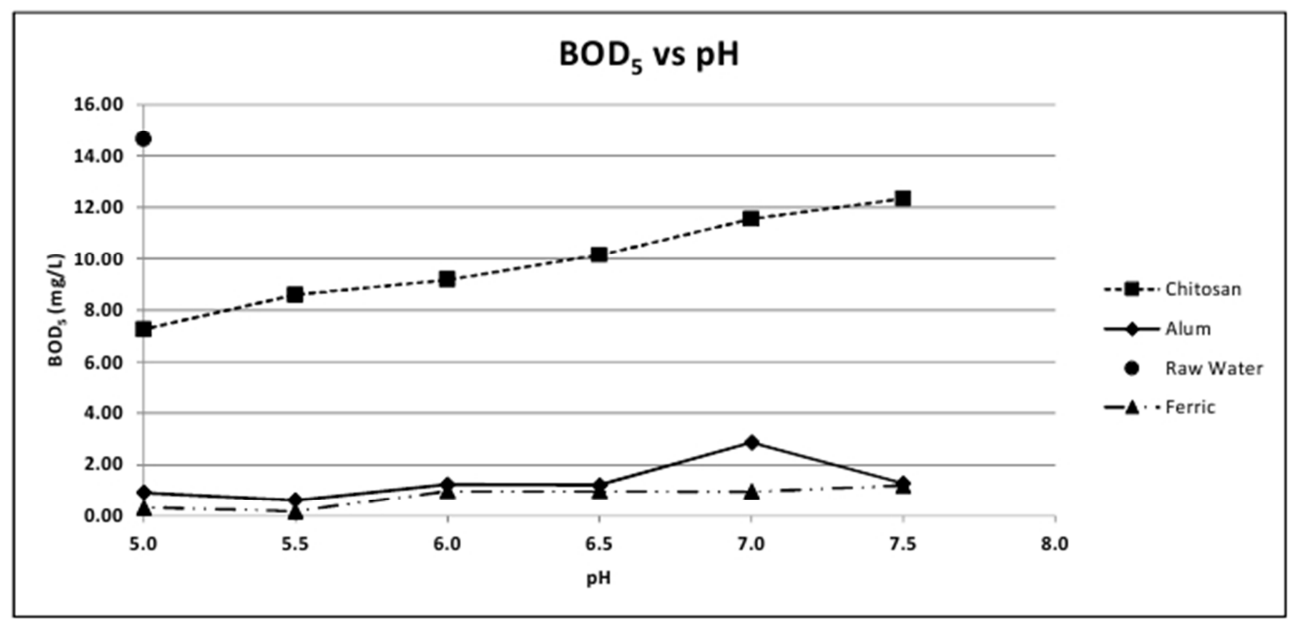

Figure 10. $B O D_{5}$ vs pH at the optimum coagulant dose. 


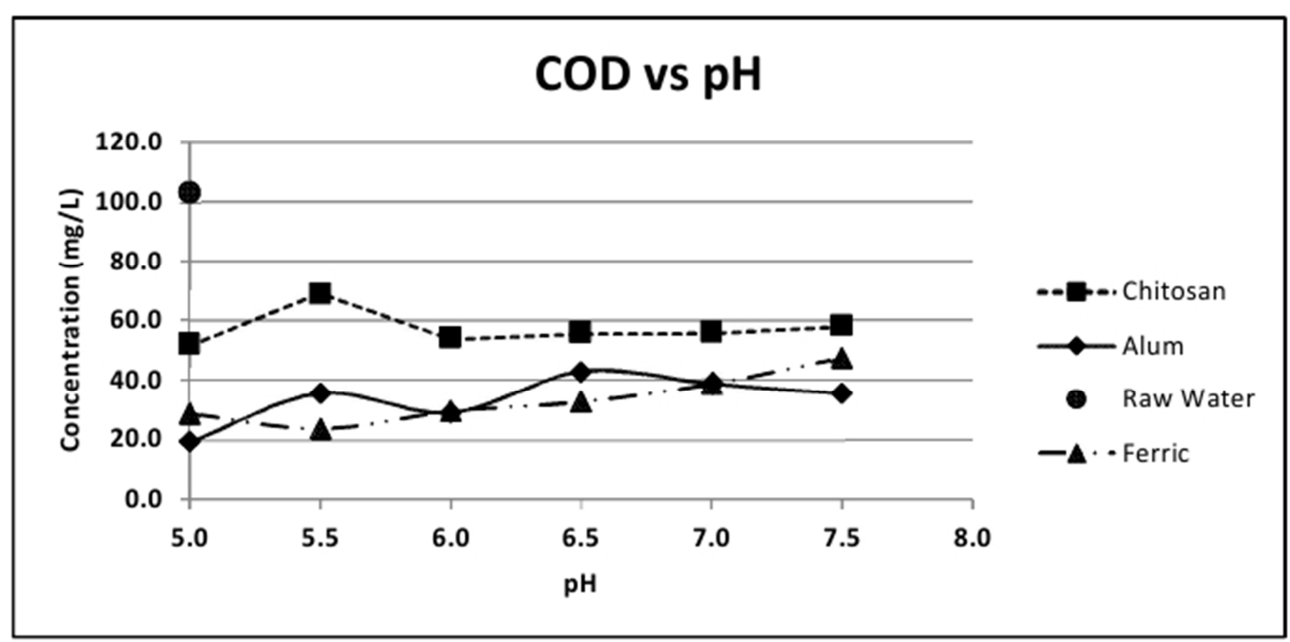

Figure 11. COD vs $p H$ at the optimum coagulant dose.

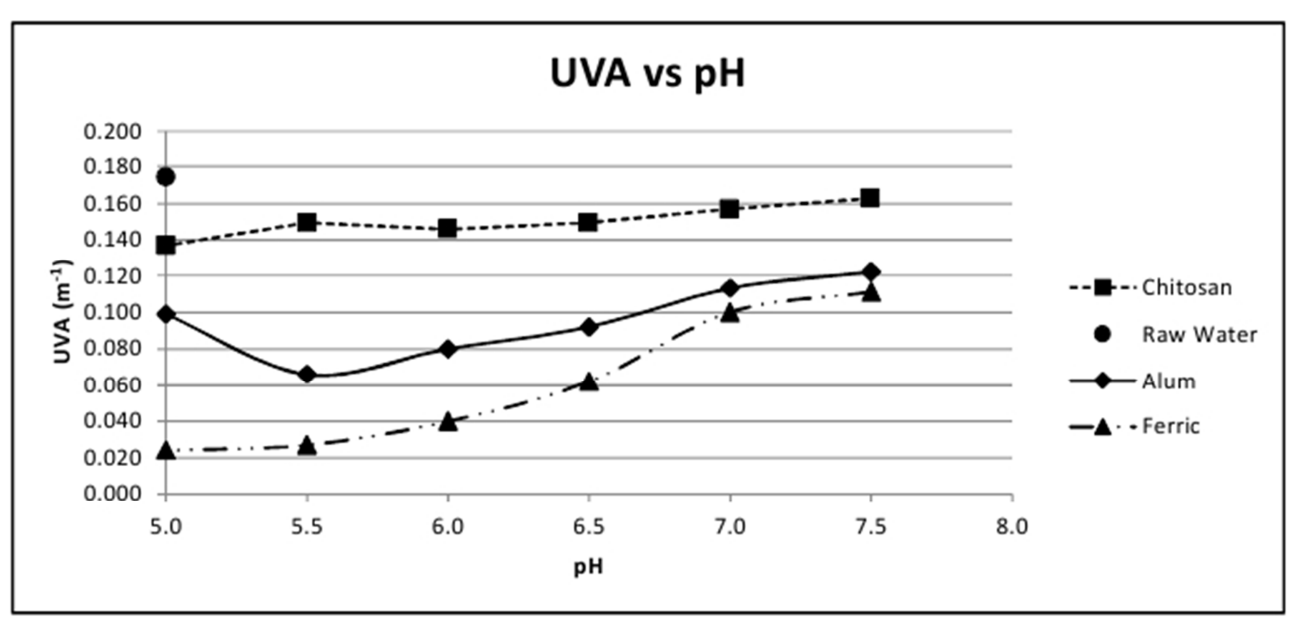

Figure 12. UVA vs pH at the optimum coagulant dose.

\subsection{Microbial Removal}

Alum and chitosan were compare for removal of total coliform and E. coli. Results for alum and chitosan are shown in Figures 13 and 14, respectively. Coliform removals for alum generally improved with increasing alum dose but were somewhat inconsistent. However, a clear point of diminishing return for removal of total coliform and $E$. coli was observed for chitosan. At the optimum dose and $\mathrm{pH}$, ferric was most effective for coliform removal and chitosan the least effective (Figure 15).

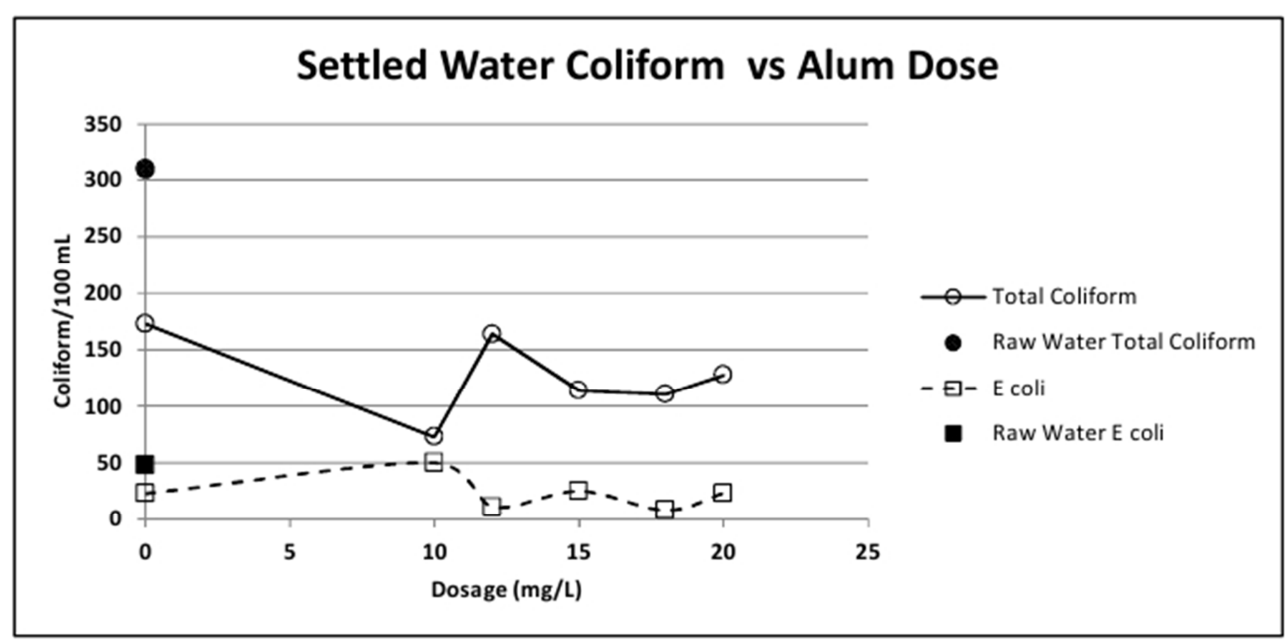

Figure 13. Settled water coliform vs alum dose. 


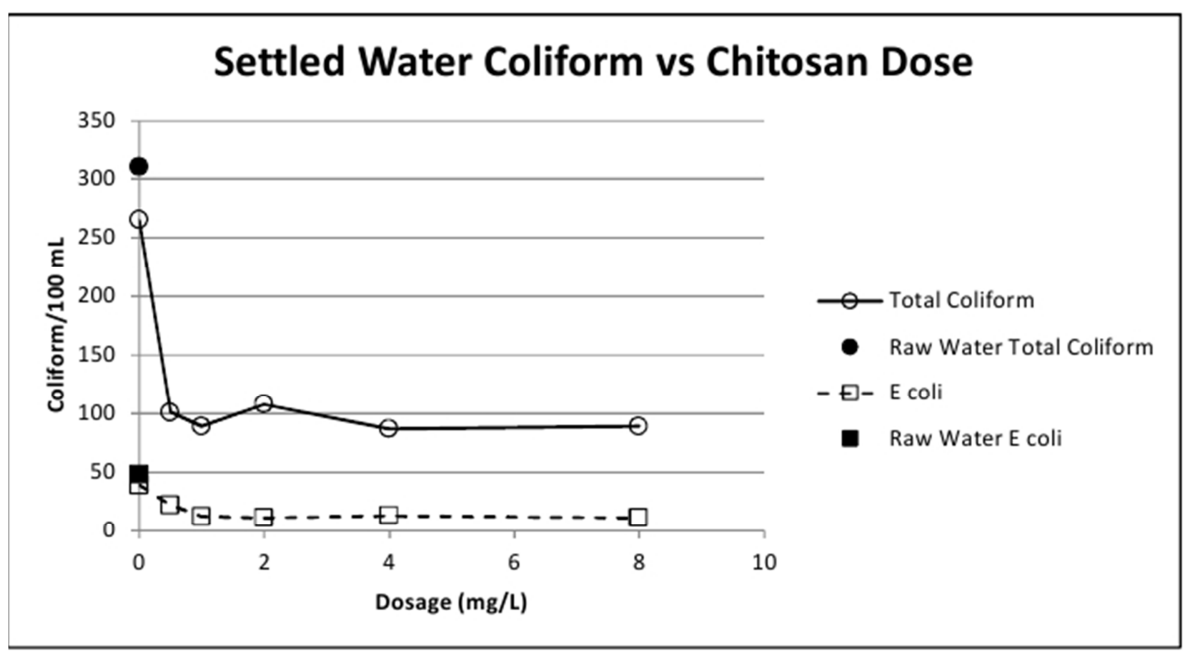

Figure 14. Settled water coliform vs chitosan dose.

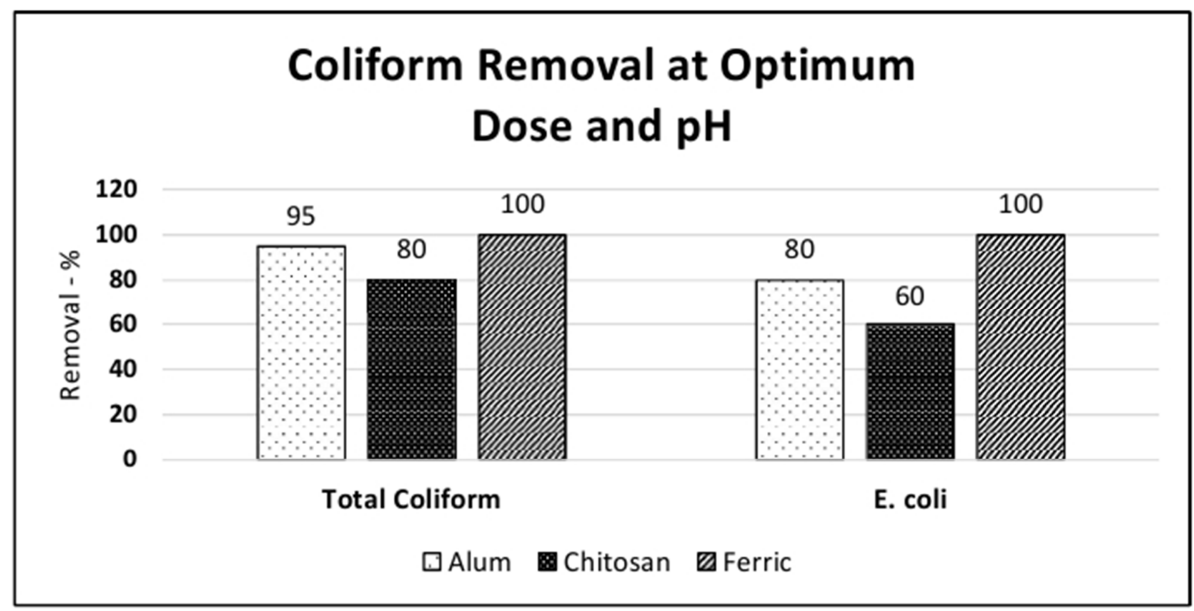

Figure 15. Coliform removal at optimum coagulant dose and $\mathrm{pH}$.

Algae removal was comparable for the three coagulants at all $\mathrm{pH}$ levels (Figure 16). As the number of algae was increased in the fourth jar test the effectiveness of all three coagulants to remove algae was generally consistent based on percent removal at the optimum coagulant dose and $\mathrm{pH}$. Alum and chitosan were equally effective coagulants (93\% removal) at an algae count of 21,000 per $\mathrm{mL}$ (Figure 17). Alum was the most effective coagulant (93\% removal) at an algae count of $22,000 \mathrm{per} \mathrm{mL}$. Alum and ferric were equally effective (93\% removal) at an algae count of 24,000 per mL. Chitosan was most effective (96\% removal) at an algae count of 37,000 per $\mathrm{mL}$. Ferric was most effective (98\% removal) at an algae count of 50,000 per $\mathrm{mL}$.

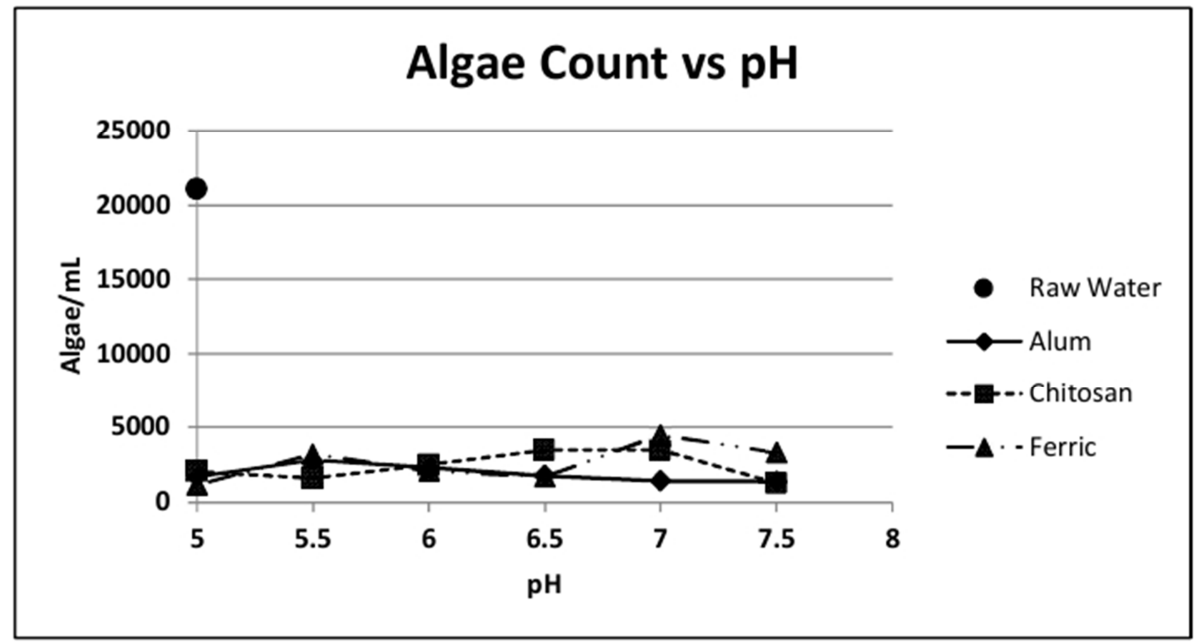

Figure 16. Algae count vs pH at the optimum coagulant dose. 


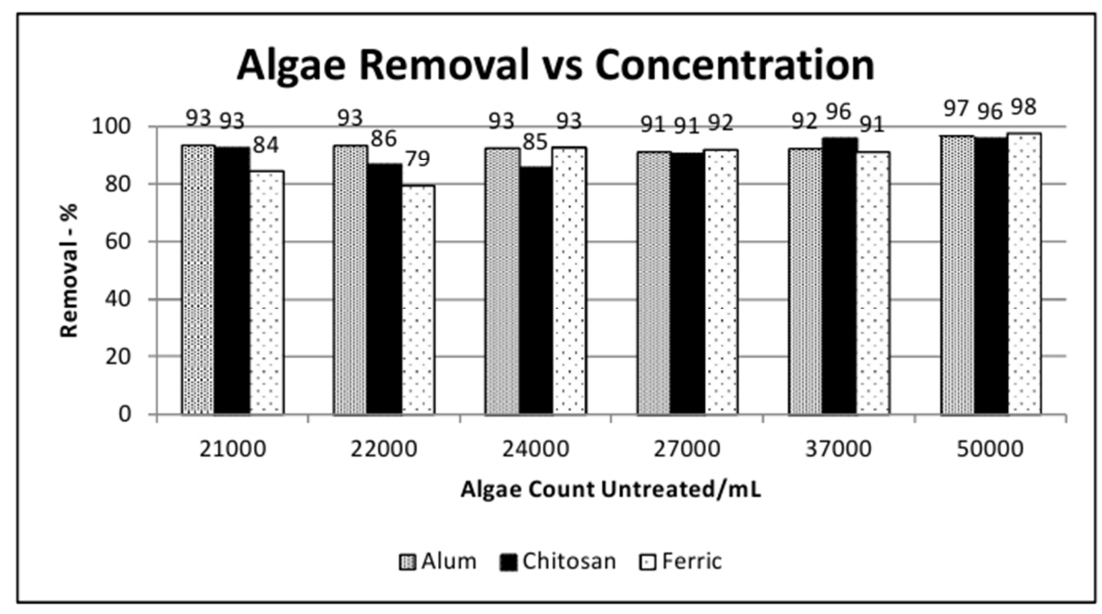

Figure 17. Algae removal percentage vs algae concentration at the optimum dose and $\mathrm{pH}$.

\subsection{Water Quality Changes}

Water quality changes at the optimum coagulant dose and $\mathrm{pH}$ were examined for $\mathrm{BOD}_{5}, \mathrm{COD}$, color, hardness, TDS, and alkalinity. Alum was most effective for removing $\mathrm{BOD}_{5}$ and $\mathrm{COD}$ followed by ferric and chitosan (Figure 18). Chitosan was most effective for removal of color followed by alum. Application of ferric at the optimum dose and $\mathrm{pH}$ for turbidity removal resulted in a substantial increase in color (orange) due to the presence of residual iron.

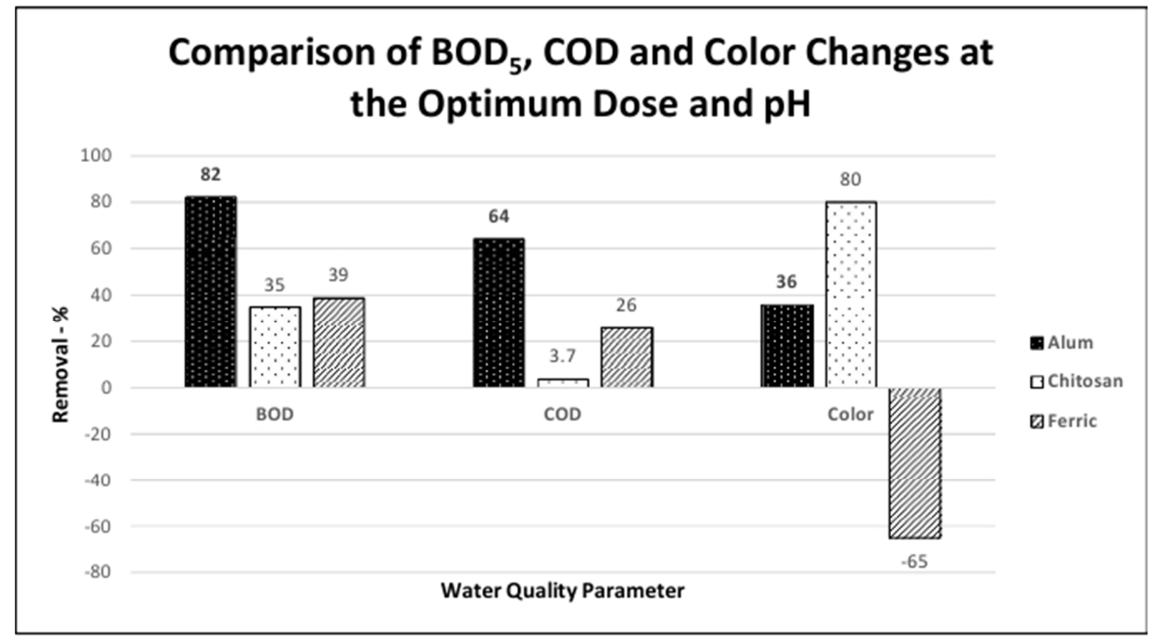

Figure 18. Changes in $B O D_{5}, C O D$, and color at the optimum dose and $\mathrm{pH}$.

In general coagulant addition had little effect on hardness (Figure 19). However, at the optimum dose and $\mathrm{pH}$, chitosan removed a small amount of hardness (22\% removal) shown in Figure 20.

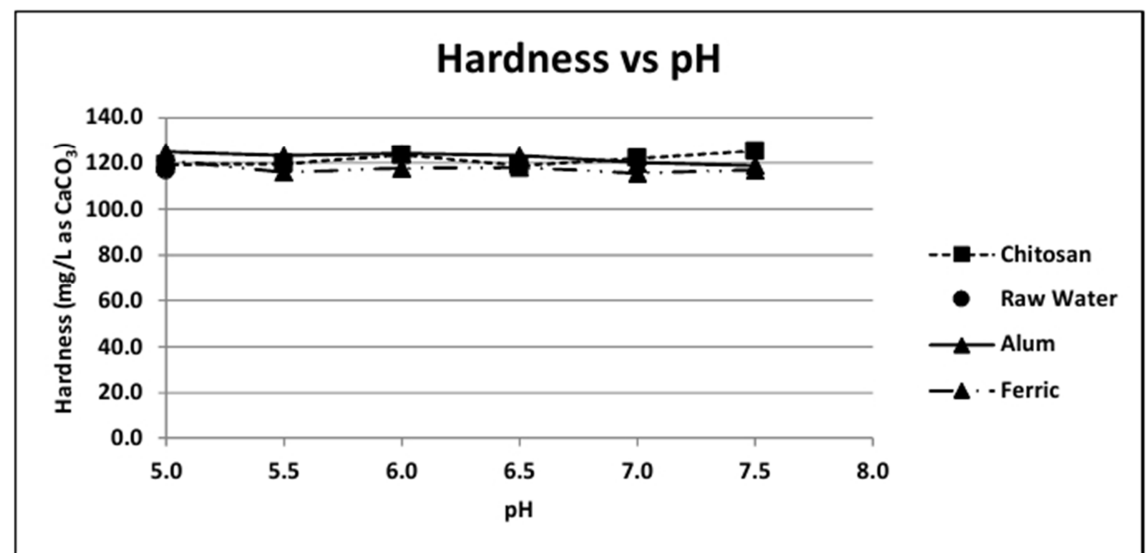

Figure 19. Settled water hardness vs pH at the optimum coagulant dose. 


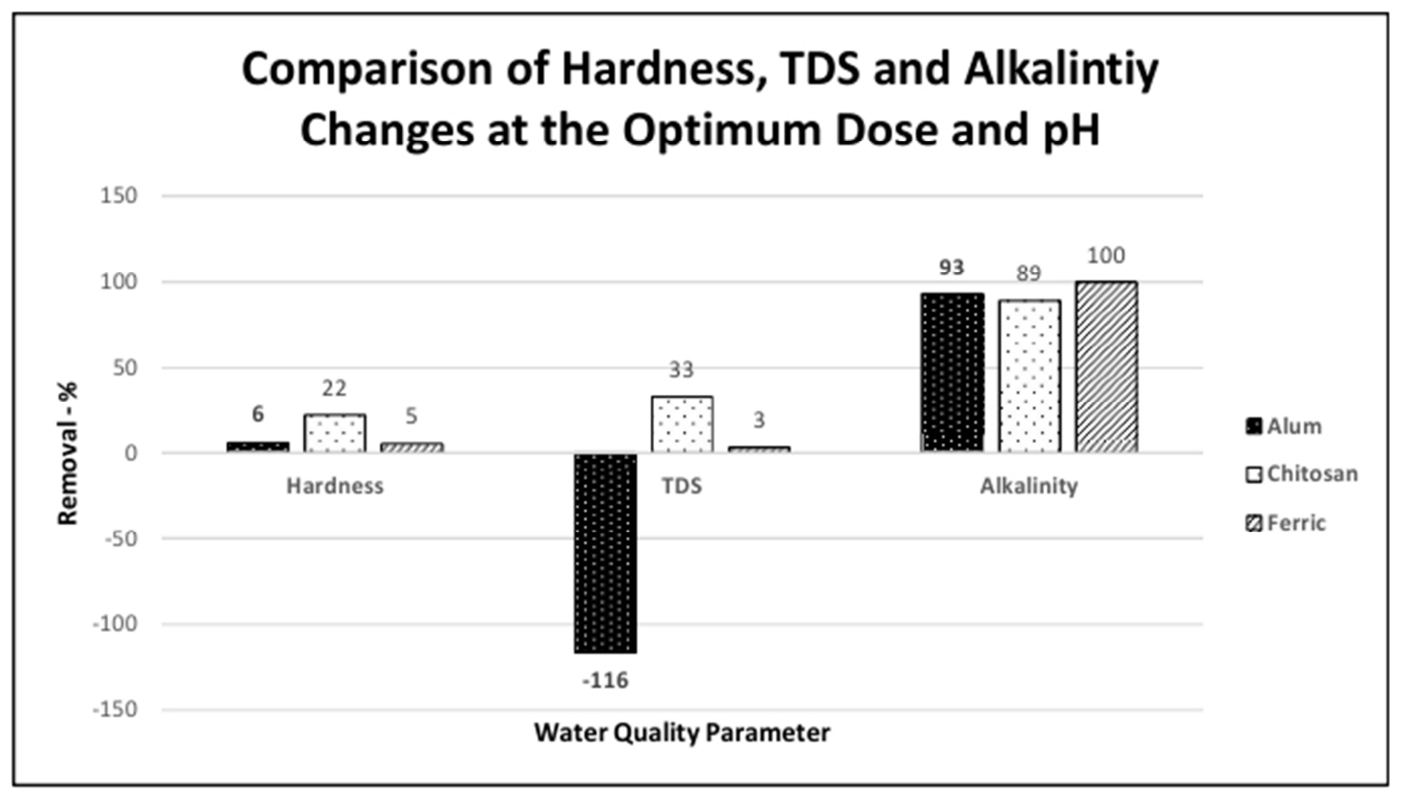

Figure 20. Hardness, TDS, and alkalinity changes at the optimum dose and $\mathrm{pH}$.

\subsection{Coagulant Comparison and Application}

Table 3 compares the performance of the three coagulants evaluated in this study. All three coagulants had a slightly acidic optimum $\mathrm{pH}$ for settled water turbidity removal. Adjusting the $\mathrm{pH}$ downward for coagulation at a full-scale treatment facility is costly. Coagulants that can perform satisfactorily, although not optimally, at near-neutral $\mathrm{pH}$ (7 to 8) are more practical. In this study, alum and ferric demonstrated more consistent turbidity removals as the $\mathrm{pH}$ increased into the neutral range and hence have a wider range of applicability. In contrast, settled water turbidity and paper filtered turbidity increased for chitosan as $\mathrm{pH}$ increased.

Table 3. Coagulant Comparison

\begin{tabular}{|c|c|c|c|}
\hline Characteristic & Alum & Chitosan & Ferric \\
\hline Optimum Dose mg/L & 30 & 8 & 30 \\
\hline Optimum pH & 6.0 & 5.5 & 5.5 \\
\hline Chemical & Inorganic salt & $\begin{array}{l}\text { Natural copolymer of glucosamine and } \\
\mathrm{N} \text {-acetyl-glucos-amine }\end{array}$ & Inorganic salt \\
\hline $\begin{array}{l}\text { Settled Water } \\
\text { Turbidity Removal }\end{array}$ & $\begin{array}{l}\text { Most effective; Consistent removal with } \\
\text { increase in } \mathrm{pH} \text { and an increase in algae count }\end{array}$ & $\begin{array}{l}\text { Somewhat effective; Less effective with } \\
\text { increase in pH; Consistent removals with } \\
\text { increase in algae count }\end{array}$ & $\begin{array}{l}\text { Effective; Consistent with } \\
\text { increase in } \mathrm{pH} \text { and an } \\
\text { increase in algae count }\end{array}$ \\
\hline Algae Removal & Effective & Effective & Effective \\
\hline $\begin{array}{l}\text { Alkalinity and } \mathrm{pH} \\
\text { impact }\end{array}$ & $\begin{array}{l}\text { Consumes alkalinity and decreases } \mathrm{pH} \text { with } \\
\text { increasing dose }\end{array}$ & Small increase in alkalinity & $\begin{array}{l}\text { Consumes alkalinity and } \\
\text { decreases pH with increasing } \\
\text { dose }\end{array}$ \\
\hline $\mathrm{BOD}_{5}$ removal & Most effective & $\begin{array}{l}\text { Somewhat effective at optimum dose and } \mathrm{pH} \text {; } \\
\text { May increase } \mathrm{BOD}_{5} \text { under some conditions }\end{array}$ & Somewhat effective \\
\hline COD removal & Most effective & Little effect & Somewhat effective \\
\hline UVA removal & Less effective at increasing $\mathrm{pH}$ & Less effective at increasing $\mathrm{pH}$ & $\begin{array}{l}\text { Less effective at increasing } \\
\mathrm{pH}\end{array}$ \\
\hline Hardness removal & Little to none & Some removal at optimum dose and $\mathrm{pH}$ & Little to none \\
\hline TDS & Increases with increasing dose & Some removal at optimum dose and $\mathrm{pH}$ & Little effect \\
\hline Color removal & Somewhat effective & Most effective for removing color & $\begin{array}{l}\text { Increases color due to } \\
\text { residual iron }\end{array}$ \\
\hline $\begin{array}{l}\text { Total Coliform and } E \text {. } \\
\text { coli removal }\end{array}$ & Effective but inconsistent & $\begin{array}{l}\text { Effective and consistent with a clear point of } \\
\text { diminishing return }\end{array}$ & Most effective \\
\hline
\end{tabular}

Chitosan demonstrated a much narrower $\mathrm{pH}$ range for acceptable turbidity removal. Within the neutral $\mathrm{pH}$ range membrane filtration was necessary to lower turbidity to acceptable levels using chitosan.

Chitosan is a natural organic polymer. Under certain conditions, an increase in $\mathrm{BOD}_{5}$ was observed in this study for chitosan caused by the presence of residual monomer [3].
Chitosan also was the least effective of the three coagulants for lowering UVA. Though not directly measured, the results presented in Table 3 suggest a higher trihalomethane formation potential for chitosan as a coagulant than for the inorganic coagulants. When present in excess, chitosan has a negative effect on performance as overdosing can restabilize a dispersion [3]. Controlling $\mathrm{pH}$ will be important if chitosan 
is to be used for drinking water treatment.

Consideration must be given to shipping, storage, and feeding of any new water treatment coagulant but especially for chitosan given its insolubility. Water treatment chemicals may be fed into the water treatment process dry or as a liquid. If chitosan is fed dry then it would be shipped in sacks or larger containers. The dry chemical would be placed into the hopper of a volumetric or gravimetric feeder, which would measure the dry powder dropping it into a day tank. This tank would have to contain dilute hydrochloric acid in order to dissolve the powder. The contents of this tank would then have to be well-mixed until the chitosan was dissolved. The resulting solution could then be fed into the treatment process using a metering pump.

If shipped as a liquid, chitosan could be dissolved and prepared as an acidic solution at the manufacturer. Liquid chemicals with a low $\mathrm{pH}$ (e.g. liquid alum) are shipped as a liquid in 50-gallon drums, 250-gallon totes, larger tank trucks, or by rail. Once delivered, the chemical solution could be fed directly from the container or placed into a larger storage tank and fed into the process using a metering pump.

Coagulation and flocculation properties of chitosan depend on the source of chitin/chitosan. Each chitosan must be characterized in terms of fraction of deacetylation, polymer weight and crystallinity because these characteristics significantly influence the physico-chemical properties of any particular chitosan. The results presented here may differ if chitosan from a different manufacturer or source was tested. Quality control and properties of chitosan on the market are not uniform across different manufacturers. Whereas quality control, product characteristics and shipping practices for inorganic coagulants (alum and ferric) are well established.

Water treatment chemicals used in the United States (also known as "direct additives") must meet industry standards to ensure that no impurities would be introduced into the treated water that present a risk to human health. Certification of water treatment chemicals under NSF Standard 60 is typically required. Chitosan is not a listed chemical under NSF Standard 60 whereas a variety of inorganic coagulants have been evaluated and are listed. Under that standard, manufacturers submit application and toxicity testing information to NSF for evaluation. Health-based limits for impurities in the chemical are set for that chemical based on the information submitted. The manufacturer bears the cost of product evaluation and listing under NSF Standard 60.

A water treatment chemical must be independently tested by a certified laboratory that it conforms to the health-based impurity limits set under NSF standard 60. If the water treatment product passes testing under NSF Standard 60 then the product is listed as being certified. In general, chemicals cannot be used for municipal water treatment in the United States unless they have been certified as meeting NSF Standard 60 and listed [15]. A state regulatory agency may impose additional requirements (e.g. pilot testing) upon a water utility and manufacturer to demonstrate the performance of any new water treatment chemical as a condition of approval.

\section{Conclusion}

The optimum coagulant dose for the lake water tested in this study based on settled water turbidity was 30,8 , and $30 \mathrm{mg} / \mathrm{L}$ for alum, chitosan, and ferric, respectively. The optimum $\mathrm{pH}$ found for coagulation to remove settled water turbidity was 6.0, 5.5, and 5.5 for alum, chitosan, and ferric, respectively. The combination of coagulation at the optimum dose, sedimentation, and paper filtration lowered treated water turbidity by 98.8 , 96.9, and 98.9 percent for alum, chitosan, and ferric, respectively. Coagulation, sedimentation, and membrane filtration was necessary for chitosan to lower treated water turbidity to below the USEPA turbidity limit of 0.3 NTU.

Removal of $\mathrm{BOD}_{5}$ by chitosan was reduced as the $\mathrm{pH}$ was increased. Treated water COD levels were higher for chitosan than for alum or ferric. Total coliform and E. coli removals demonstrated a clear point of diminishing return for chitosan. Algae removal as a percentage was consistent for all coagulants as algae counts were increased. Chitosan was the most effective coagulant of the three for removal of color. At the optimum dose and $\mathrm{pH}$, chitosan removed a small amount of hardness ( $22 \%$ removal).

Chitosan demonstrated a much narrower $\mathrm{pH}$ range for acceptable turbidity removal when compared to alum and ferric. Overdosing of chitosan can result in restabilization of a dispersion so $\mathrm{pH}$ adjustment will be needed to avoid excess monomer if chitosan is used as a water treatment coagulant.

Several practical considerations must be addressed before chitosan could be considered a viable alternative to alum or ferric for municipal water treatment. These include the quality, form and manner of product availability from the manufacturer (dry or liquid), shipping of the product, and specification of the equipment needed to feed the chemical at full-scale. As with any new water treatment chemical, chitosan-based coagulants must be certified as meeting NSF Standard 60 for direct additives before being considered for drinking water treatment in the United States.

\section{Acknowledgements}

This study was funded by a Microgrant from the California Baptist University Faculty Development Committee. Civil Engineering undergraduate students Ryan Gibeault and Matthew Biggs assisted with performing laboratory analyses.

\section{References}

[1] Nogaro, G. and A. J. Burgin, V. A. Schoepfer, M. J. Konkler, K. L. Bowman, and C. R. Hammerschmidt. 2013. Aluminum sulfate (alum) application interactions with coupled metal and nutrient cycling in a hypereutrophic lake ecosystem. Environmental Pollution, vol. 176, 2013, pp. 267-274.

[2] M. Rinaudo. "Chitin and chitosan: Properties and applications," Progress in Polymer Science, vol. 31, 2006, pp. 603-632.

[3] F. Renault, B. Sancey, P.-M. Badot, G. Crini. "Chitosan for coagulation/flocculation processes - An eco-friendly approach" European Polymer Journal, vol. 45, 2009, pp. 1337-1348. 
[4] S. A. Fast, B. Kokabian and V. G. Gude. "Chitosan enhanced coagulation of algal turbid waters - Comparison between rapid mix and ultrasound coagulation methods." Chemical Engineering Journal, vol. 244, 2014, pp. 403-410.

[5] H. Altaher. "The use of chitosan as a coagulant in the pre-treatment of turbid sea water." Journal of Hazardous Materials, vol. 233-234, 2012, pp. 97-102.

[6] A. L. Ahmad, N. H May Yasin, J. C. Derek, and J. K. Lim. "Optimization of Microalgae Coagulation Processes Using Chitosan." Chemical Engineering Journal, vol. 173, 2011, pp. 879-882.

[7] M. A. Abu Hassan and M. H. Puteh. "Pretreatment of palm oil effluent (POME): a comparison study using chitosan and alum." MJCE, vol. 19, 2007, 128-141.

[8] R. Yang, H. Li, M. Huang, H. Yang, A. Li. "A review on chitosan-based flocculants and their applications in water treatment." Water Research, vol. 95, 2016, pp. 59-89.

[9] EPA. Manual for the Certification of Laboratories Analyzing Drinking Water; Criteria and Procedures Quality Assurance. Fifth edition. EPA 815-R-05-004. January 2005.
[10] R. Divakaran and V. N. Sivasankara Pillai. "Flocculation of algae using chitosan." Journal of Applied Phycology, vol. 14, 2001, 419-422.

[11] ASTM D 2035-08, "Standard Practice for CoagulationFlocculation Jar Test of Water." West Conshohocken, PA: American Society for Testing and Materials.

[12] APHA. Standard Methods for the Examination of Water and Wastewater. $20^{\text {th }}$ Edition. Washington, D. C.: American Public Health Association, 1998.

[13] Hach Method 10029. USEPA Membrane Filter Method. Coliforms - Total and E. coli. DOC316.53.001213.

[14] L. Rizzo, A. Di Gennaro, M. Gallo, and V. Belgiorno. "Coagulation/chlorination of surface water: a comparison between chitosan and metal salts." Separation and Purification Technology, vol. 62, 2008, 79-85.

[15] NSF Standard 60-2015. Drinking Water Treatment Chemicals - Health Effects. Ann Arbor, MI: NSF International. 